\title{
Proportions of Atlantic sailfish (Istiophorus platypterus) and spearfish (Tetrapturus pfluegeri) caught in tuna longline fisheries
}

\author{
Renata Maria Medeiros-Silva $\cdot$ Humber Agrelli Andrade
}

Received: 28 May 2016/Accepted: 27 October 2016/Published online: 9 November 2016

(C) The Author(s) 2016. This article is published with open access at Springerlink.com

\begin{abstract}
The reliability of estimations of catches of pelagic longline fisheries is especially worrying in the case of non-target species such as the sailfish (Istiophorus platypterus) and spearfish (Tetrapturus pfluegeri), because they are often recorded aggregated in onboard maps. For this reason, generalized linear models were used to identify a number of important explanatory variables and their effect on sailfish and spearfish proportions. The response variable (number of sailfish in the aggregate capture) is assumed as binomial using the logit link function. The explanatory variables used were foram year, qrt (quarter), fleet, de (distance from equator) and $d$ (distance from areas above sea level). The selected models showed that the equatorial and coastal regions presented higher densities or catchabilities of sailfish when compared to spearfish, as in the case for fleets of China Taipei and the United States. The lowest mean proportion of sailfish [sailfish/ (sailfish + spearfish)] of the third quarter were driven mostly by the low estimations calculated for Japan and Brazil.
\end{abstract}

Keywords Generalized linear models $\cdot$ Variables $\cdot$ Fishery $\cdot$ Bycatch

\section{Introduction}

Several migratory species such as tuna (Thunnus sp.), swordfish (Xiphias gladius) and some sharks (e.g., blue shark Prionace glauca) are targeted by fisheries carried out by pelagic longline (Watson and Kerstetter 2006; Cortés et al. 2010; Abecassis et al. 2012); and many countries exploit these resources in the Atlantic ocean, such as Brazil, China Taipei, Spain, United States, Japan and Venezuela. Despite the fact that pelagic longline fisheries usually prioritize the most abundant and valuable species in the market, they are multispecific, that is, there is a large amount of bycatch, including billfish (Goodyear 1998).

Catches of all animals should normally be recorded in detail by fishermen or onboard observers; however, species that are not targeted by longline fisheries generally have their catches omitted and in some cases they are not adequately discriminated which results in the underestimation of mortality, affecting the evaluation of stocks and causing bad decisions in the management of fisheries (Bellido et al. 2011). Other problem is to report the catches of different species in combination, exemplified in the case of sailfish (Istiophorus platypterus) and spearfish (Tetrapturus pfluegeri) in the Atlantic. Part of the catch of these two species is also inserted into the category of "billfish unclassified" in the database of the International Commission for the Conservation of Atlantic Tunas (ICCAT) (ICCAT 2014).

R. M. Medeiros-Silva $(\bowtie) \cdot H$. A. Andrade

Department of Fisheries and Aquaculture, Federal Rural University of Pernambuco, P.O. Box 52171-900, Recife, Brazil e-mail: eng.pescarenata@yahoo.com.br 
The aggregation of sailfish and spearfish catches hinders the acquisition of more in-depth knowledge about the fishery biology of these species. Hence, it is important to conduct a joint analysis to understand the contribution of each one in longline fisheries, that is, to study the temporal, spatial and fishing effects on the proportions of the nominal catch of each species. Therefore, the objective of this study was to structure and adjust a model, and to identify a number of important explanatory variables and their effect on the proportions of sailfish (SAI) and spearfish (SPF).

\section{Materials and methods}

Data

The data used in this study were provided by the ICCAT Secretariat at the evaluation meeting of sailfish stocks held in 2009 (ICCAT 2010). The database contains information on the number of sailfish and spearfish caught by latitude and longitude (resolution of $5^{\circ}$ ), by fleet, by quarter and in some cases by year.

The total number of billfish per year and the proportions of sailfish for fleets from Brazil, the United States (US) and Venezuela are listed in Table 1. There is no information broken down by year for fleets of China Taipei, Spain and Japan. It is worth noting that information on fisheries of the Brazilian fleet is available only from 2004, although the sample size is large. In the case of the fleets of the United States and Venezuela the sample sizes are smaller, but time series are long.

Table 1 Sum of sailfish and spearfish

\begin{tabular}{|c|c|c|c|}
\hline Year & Brazil & United States & Venezuela \\
\hline 1987 & & & $30(1.000)$ \\
\hline 1988 & & & $7(1.000)$ \\
\hline 1989 & & & $19(1.000)$ \\
\hline 1990 & & & $33(0.697)$ \\
\hline 1991 & & & $131(0.771)$ \\
\hline 1992 & & $86(0.930)$ & $186(0.785)$ \\
\hline 1993 & & 407 (0.907) & 294 (0.799) \\
\hline 1994 & & $152(0.855)$ & $386(0.666)$ \\
\hline 1995 & & $137(0.898)$ & $438(0.555)$ \\
\hline 1996 & & $214(0.893)$ & $254(0.528)$ \\
\hline 1997 & & $240(0.929)$ & $188(0.585)$ \\
\hline 1998 & & $57(0.860)$ & $310(0.645)$ \\
\hline 1999 & & & $221(0.833)$ \\
\hline 2000 & & $259(0.988)$ & $115(0.609)$ \\
\hline 2001 & & $72(0.833)$ & $102(0.422)$ \\
\hline 2002 & & $69(0.623)$ & $101(0.356)$ \\
\hline 2003 & & $54(0.889)$ & $287(0.254)$ \\
\hline 2004 & $12452(0.685)$ & $81(0.914)$ & $245(0.486)$ \\
\hline 2005 & $14459(0.756)$ & $115(0.930)$ & $283(0.420)$ \\
\hline 2006 & $3131(0.634)$ & $67(1.000)$ & $450(0.418)$ \\
\hline 2007 & $1539(0.561)$ & $126(0.984)$ & $181(0.829)$ \\
\hline 2008 & $595(0.603)$ & & $225(0.711)$ \\
\hline \multirow[t]{2}{*}{ Total } & $32176(0.648)$ & $2136(0.895)$ & $4486(0.653)$ \\
\hline & China Taipei & Japan & Spain \\
\hline Total & $11704(0.834)$ & $54834(0.487)$ & $2075(0.663)$ \\
\hline
\end{tabular}

In brackets the proportion of sailfish (SAI/[SAI $+\mathrm{SPF}])$ 
Models and variables

Generalized linear models (GLM) (McCullagh and Nelder 1989; Dobson 2002) were used to analyze the dataset, which include only catches of sailfish or spearfish hence the response variable $(Y)$ is binary. "Success" (1) was attributed to the occurrence of sailfish while "failure" $(0)$ was attributed to the non-occurrence of sailfish, that is, to the occurrence of spearfish, thus we have assumed that $Y$ follows a binomial distribution. In the GLMs it is necessary to specify the link function between the expectation (mean) of response variable and the linear predictor. We have used the logit function, which is often used as a link when the assumed distribution is binomial (Dobson 2002). All analyses and graphs were performed using R software 3.1.3 (R Development Core Team 2015). Packages "mapdata', "maps" and "sp" were used for maps, while $g \operatorname{lm}()$ function was used to fit the models and estimate the parameters by using an iterative algorithm of weighted least squares (Charnes et al. 1976).

For the explanatory variables, the study considered year (1987-2008), quarter (January-March, AprilJune, July-September, October-December) and fleet (Brazil, US, Venezuela, China Taipei, Spain and Japan) as factors, and also distances of fishing locations in relation to the equator and to the areas above sea level as covariates. Results gathered in the exploratory analyses contain evidence that sailfish proportions are larger as fisheries approach the equator or areas above sea level. This was the motivation for the calculation of distances as potential explanatory variables.

The distance from the fishing location to the equator was calculated in kilometers by:

$$
\text { de }=\mid \text { latitude } \mid \cdot 111.32 / 1000
$$

The distances from areas above sea level were calculated from the projection of eight radial trajectories with angles $r=\left\{0^{\circ}, 45^{\circ}, \ldots, 315^{\circ}\right\}$ (Fig. 1). At the end there is a distance vector $d=\left\{d_{1}, \ldots, d_{8}\right\}$ corresponding to vector $r$. Radial trajectories with angles $45^{\circ}, 135^{\circ}, 225^{\circ}$ and $315^{\circ}$ suffer distortions due to the Earth's curvature. The equations used to calculate the trajectories with adjustments for these distortions are (Veness 2015):

$$
\begin{gathered}
\mathrm{la}_{j}=\operatorname{arcsen}\left(\operatorname{sen}\left(\mathrm{la}_{i}\right) \cos (d / R)+\cos \left(\mathrm{la}_{i}\right) \operatorname{sen}(d / R) \cos (\theta)\right) \\
1 \mathrm{o}_{j}=1 \mathrm{o}_{i}+\arctan ^{2}\left(\operatorname{sen}(\theta) \operatorname{sen}(d / R) \cos \left(1 \mathrm{a}_{i}\right) \cdot \cos (d / R) \operatorname{sen}\left(1 \mathrm{a}_{i}\right) \operatorname{sen}\left(l a_{j}\right)\right)
\end{gathered}
$$

in which la and lo are latitude and longitude of $i$ th fishing position and $j$ th point belonging to the radial trajectory with bearing angle $\theta$. The angle between the $x$ axis and the vector of origin of the trajectory until the position defined by the coordinates $(x, y)$ is calculated with function $\arctan ^{2}(x, y) . d$ is the distance from position $1 \mathrm{l}_{i}$ and $\mathrm{la}_{i}$ to position $\mathrm{lo}_{j}$ and $\mathrm{la}_{j}$, and $R$ is the average radius of the Earth $(\approx 6.371 \mathrm{~km})$. Variables $d$ and $d e$ are in thousands of kilometers.

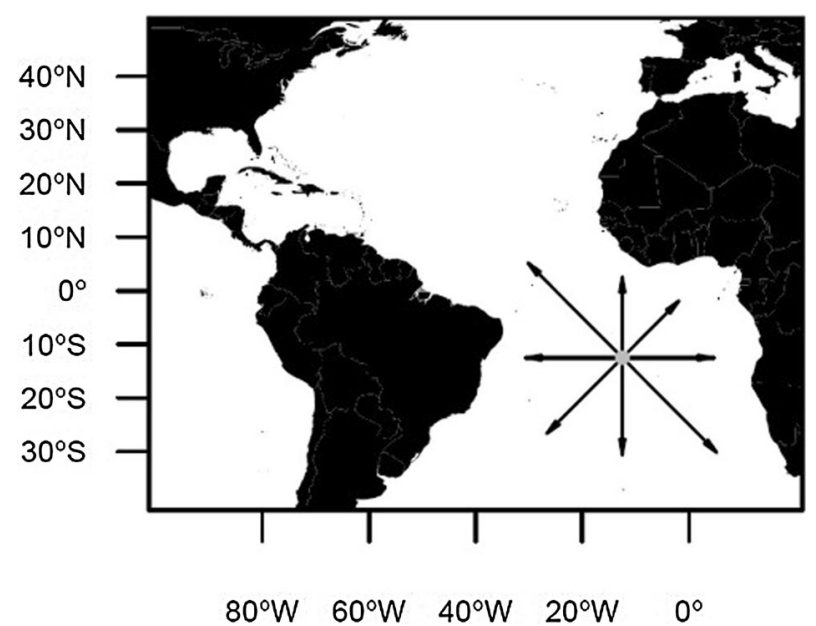

Fig. 1 Eight heading radial directions used to calculate distances from fishing locations (gray circle at the origin of arrows) to the coastal shorelines 
The explanatory variables calculated based on the distance vector of areas above sea level $d$, were minimum distance $\left(d_{(\min )}\right)$, and the mean of the $k$ smaller distances of areas above sea level $\left(d_{(k)}\right)$. The mean of the $k$ smaller distances was used as an indicative that fishing operation was located near mainland or islands, or even near more complex coastal formations. In this paper we have used $k=2$ or $k=3$.

Potential transformations of all variables related to distance calculations ( $d$ and $d e$ ) were considered in the models-more specifically functions $f$ (distance) $=(\text { distance })^{p}$ with $p=\{1 / 2,1,2,3\}$ were considered as explanatory variables. Exponents different of 1 allow for the assessment of the existence of nonlinear relationships between response and explanatory variables.

Four $p$ values were evaluated for the transformation of distance from the equator $(1 / 2,1,2,3)$, three distance measurements from areas above sea level $\left(d_{(\min )}, d_{(2)}\right.$ and $\left.d_{(3)}\right)$ and four $p$ values for transformations of $d(1 / 2,1,2,3)$, resulting in $4 \times 3 \times 4=48$ different models according to the combination of covariates. None of the assessed models included more than one of the potential transformations of the distances mentioned above as explanatory variable, since the correlation among them are high. There are two scenarios that refer to the inclusion or not of the year variable, thus there are a total of $2 \times 48=96$ adjusted models.

\section{Construction and selection of models}

Different design matrices can be used in the generalized linear model framework. This study used a "corner point" matrix; for more details on this procedure see Dobson (2002). Models with all main effects and all first order interactions are here denominated as complete models.

The order of the explanatory variables entered in the models was selected based on calculations of deviance which is a discrepancy index. Small models with each of the explanatory variables were fitted to data. The smaller the deviance the further ahead the explanatory variable was located in the complete model. The interactions were included after choosing the initial order of main effects. Later, to select the explanatory variables and interactions to be in or dropped from the models, the Akaike Information Criterion (AIC) was used (Akaike 1974); and for comparison purposes, "weights of evidence" were calculated based on the AIC (Burnham and Anderson 2002):

$$
w_{i}=\exp \left(-0.5 \Delta_{i}\right) / \sum_{r=1}^{R} \exp \left(-0.5 \Delta_{i}\right)
$$

where $w_{i}$ is the favorable weight of evidence to the $i$ th model, and $\Delta_{i}=\mathrm{AIC}_{i}-\mathrm{AIC}_{\min }$ is the difference between the AIC of the $i$ th model and the minimum AIC found in all the $R=48$ models evaluated for each of the two scenarios (with or without year).

After choosing models based on estimates of AICs and weights of evidence, analyses of residuals were carried out to assess the quality of the adjustments (Dobson 2002). The interpretation of the estimated coefficients for the factors (year and fleet) and distances ( $d$ and $d e$ ), was carried out using graphs of the predictions of the expected proportions obtained after adjusting the models.

\section{Results}

Exploratory analysis

There are differences among the operation areas of all fleets (Fig. 2). Brazilian vessels worked near equatorial tropical areas of the southern hemisphere, while the US fleet operated in the Gulf of Mexico, the North Caribbean and surroundings of the state of Florida. The Venezuelan fleet operated just above the equator, in tropical regions of the western North Atlantic. Japan had extensive operations in both the North and South Atlantic Ocean. Spain carried out fisheries near the African continent in the vicinities of the equator and in tropical and subtropical regions, especially in the southern hemisphere. The fleet of China Taipei acted extensively in both hemispheres, concentrating its operations around the equatorial region. 


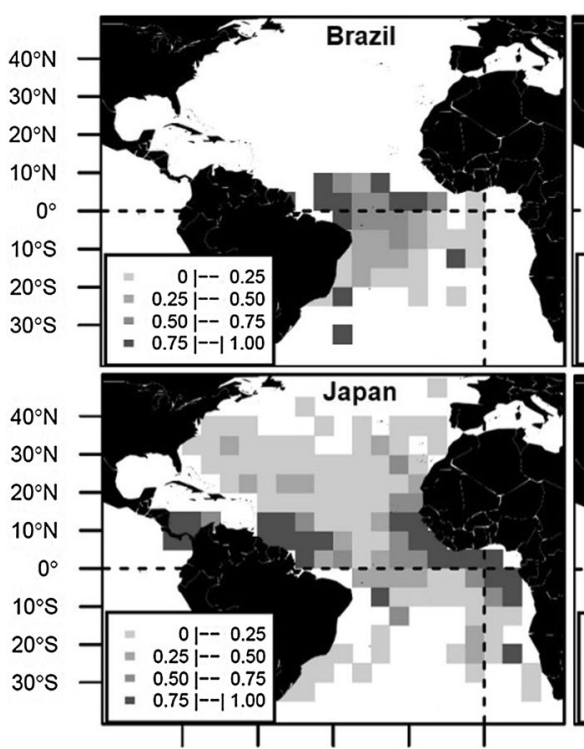

$80^{\circ} \mathrm{W} \quad 60^{\circ} \mathrm{W} \quad 40^{\circ} \mathrm{W} \quad 20^{\circ} \mathrm{W} \quad 0^{\circ}$
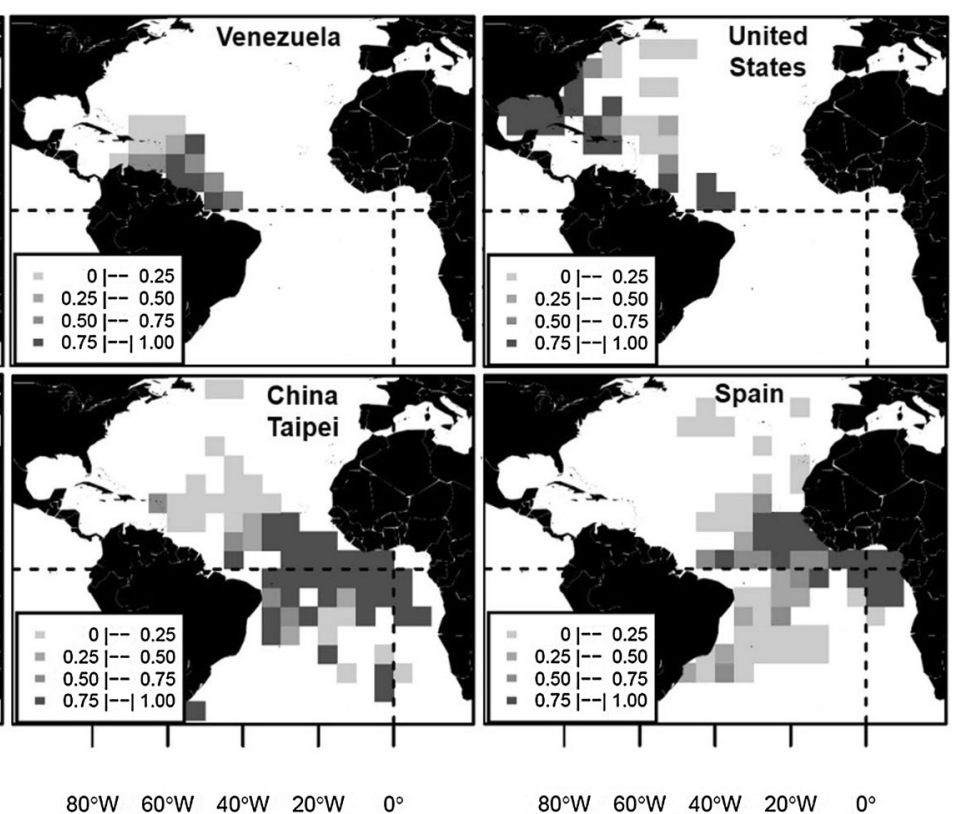

Fig. 2 Proportion of sailfish in relation to the total (sailfish plus spearfish) in the catches of fleets from Brazil, United States, Venezuela, Japan, China Taipei and Spain

Selected models

The best models for each of the two scenarios (with year and without year) are shown in Table 2. There was clearly a "winner" model for each scenario as indicated by the values of the "weights of evidence" close to 1. All explanatory variables and interactions considered were selected in the top ranked models. The explanatory variables are in descending order of importance.

Table 2 Models for each of the two scenarios (with or without year)

\begin{tabular}{lrr}
\hline Scenarios and models & AIC & Weight \\
\hline With year & & $9.99 \times 10^{-1}$ \\
Response $\sim\left(\right.$ year + fleet $\left.+d e^{1 / 2}+q t r+d_{(\mathrm{min})}\right)$ & 4967.71 & $6.51 \times 10^{-5}$ \\
Response $\sim\left(\right.$ year + fleet $\left.+d e+q t r+d_{(\mathrm{min})}\right)$ & 4986.98 & $4.93 \times 10^{-9}$ \\
Response $\sim\left(\right.$ year + fleet $\left.+d e^{1 / 2}+q t r+d_{(\mathrm{min})}^{1 / 2}\right)$ & 5005.96 & $1.40 \times 10^{-12}$ \\
Response $\sim\left(\right.$ year + fleet $\left.+d e+q t r+d_{(\min )}^{1 / 2}\right)$ & 5022.28 & $3.20 \times 10^{-18}$ \\
Response $\sim\left(\right.$ year + fleet $\left.+d e^{1 / 2}+q t r+d_{(\min )}^{2}\right)$ & 5048.27 & $9.99 \times 10^{-1}$ \\
Without year & & $6.63 \times 10^{-4}$ \\
Response $\sim\left(d e^{2}+d_{(2)}^{1 / 2}+\right.$ fleet $\left.+q r t\right)$ & $17,111.10$ & $3.17 \times 10^{-147}$ \\
Response $\sim\left(d e+d_{(2)}^{1 / 2}+\right.$ fleet $\left.+q r t\right)$ & $17,785.75$ & $2.60 \times 10^{-154}$ \\
Response $\sim\left(d e+d_{(3)}^{1 / 2}+\right.$ fleet $\left.+q r t\right)$ & $17,818.38$ & $3.24 \times 10^{-172}$ \\
Response $\sim\left(d e^{2}+d_{(3)}^{1 / 2}+\right.$ fleet $\left.+q r t\right)$ & $17,900.83$ & \\
Response $\sim\left(d e^{2}+d_{(\min )}^{1 / 2}+\right.$ fleet $\left.+q r t\right)$ & & \\
\hline Response $)$ & & \\
\hline
\end{tabular}

Response variable is the proportion sailfish/(sailfish + spearfish), explanatory variables are year, fleet, quarter (qrt), distance from equator $(d e)$, minimum distance from areas above sea level $\left(d_{(\min )}\right)$, averages of two minimum distances $\left(d_{(2)}\right)$ and of three minimum distances $\left(d_{(3)}\right)$ from areas above sea level as calculated according to eight heading radials starting from the fishing location. The exponents stand for algebraic operations 

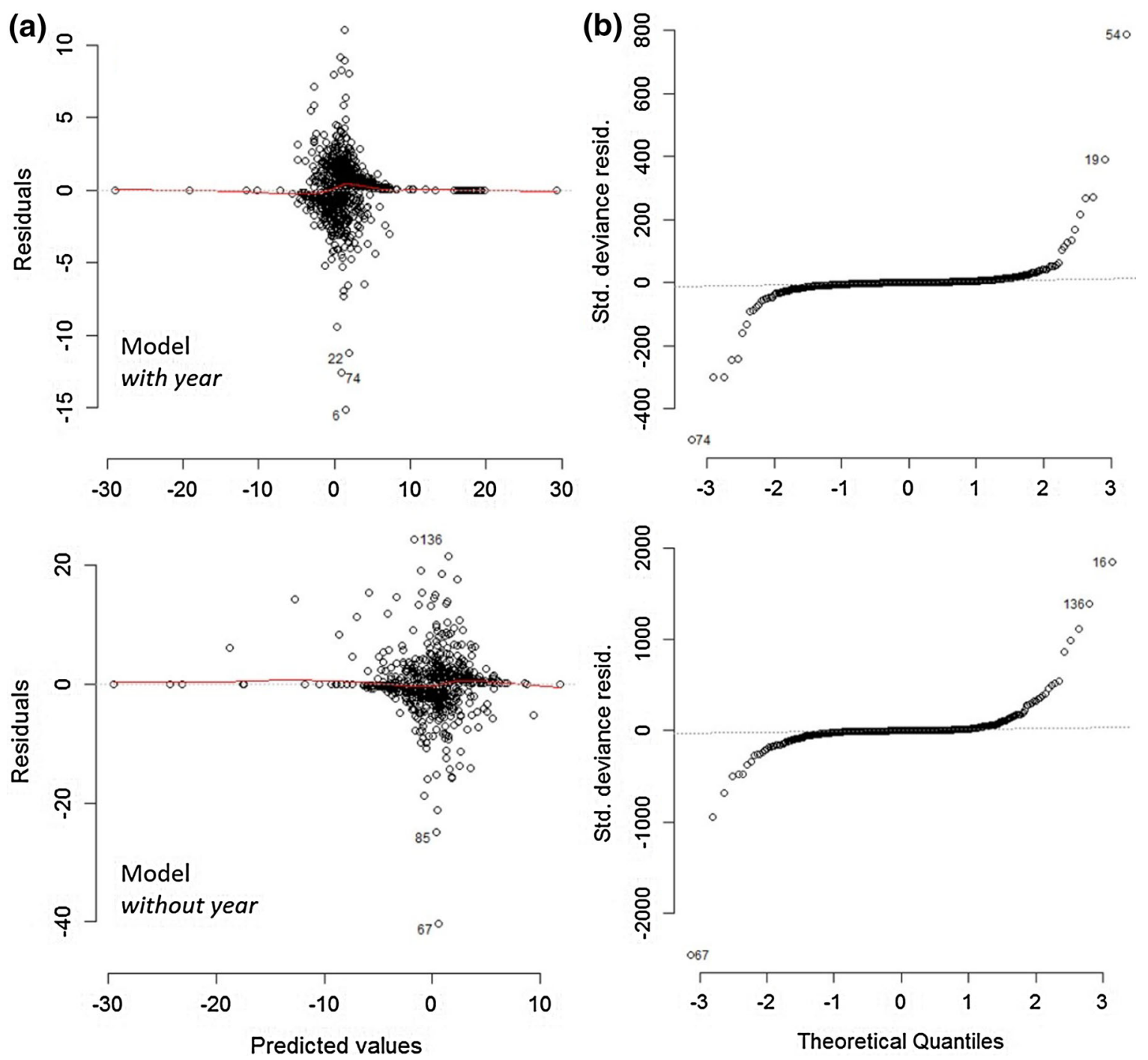

Fig. 3 Diagnostics of adjustment of models with and without year. a Relationship between fitted and residuals and $\mathbf{b}$ normal quantile plot of residuals

Analysis of residuals

There is homoscedasticity of the residuals in all scenarios and models analyzed (Fig. 3a). There is also evidence that there is no strong bias in the estimates. The observations that correspond to higher standardized residuals have reduced leverage power. Few values with high Cook's distances appear in the calculations, but a sensitivity analysis verified that they do not strongly affect the estimates. The residuals also have an approximately normal distribution with some violations only for a few tail points (Fig. 3b). By virtue of the above mentioned, the adjustments of the models were considered satisfactory.

Effect of the explanatory variables

\section{Scenario with year}

In order to calculate marginal estimations of sailfish proportions of different years and fleets, the distance from the equator $(d e)$ was fixed at 0.527 and the minimum distance of areas above sea level $\left(d_{(\mathrm{min})}\right)$ at 0.184 thousands of kilometers. The choice of this position was random among those in which there was high effort 


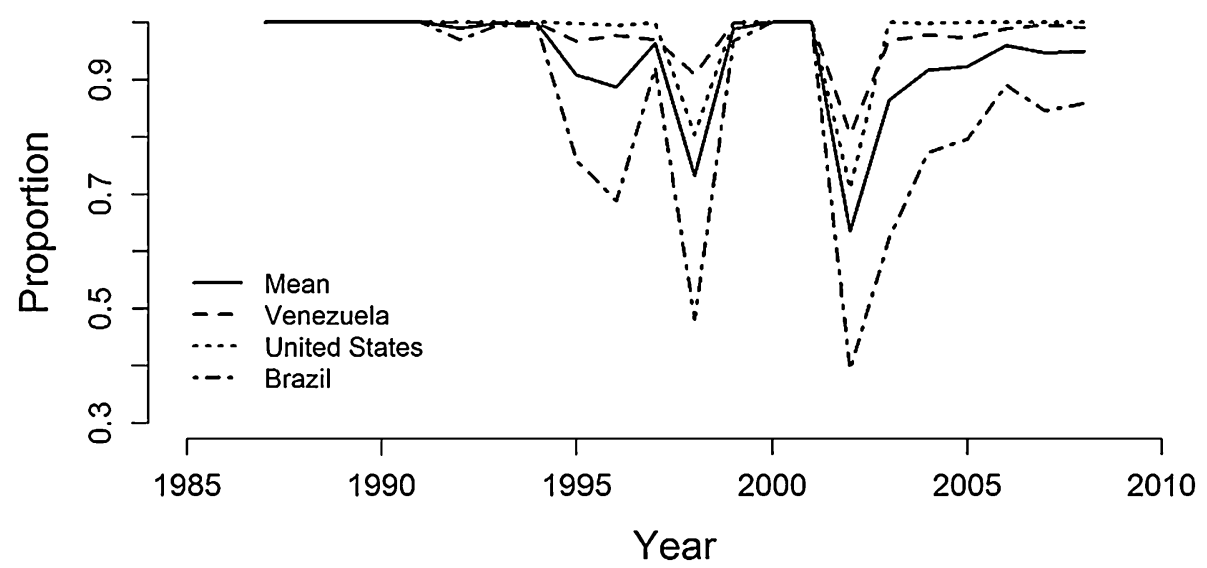

Fig. 4 Estimates of sailfish proportions sailfish/(sailfish + spearfish) according to the year factor for fleets of Venezuela (VNZ), United States (US), Brazil (BRA), and for grouped fleets (mean) fixing the distance from the equator (de) at 0.527 and the minimum distance from areas above sea level $\left(d_{(\mathrm{min})}\right)$ at 0.184 thousand kilometers

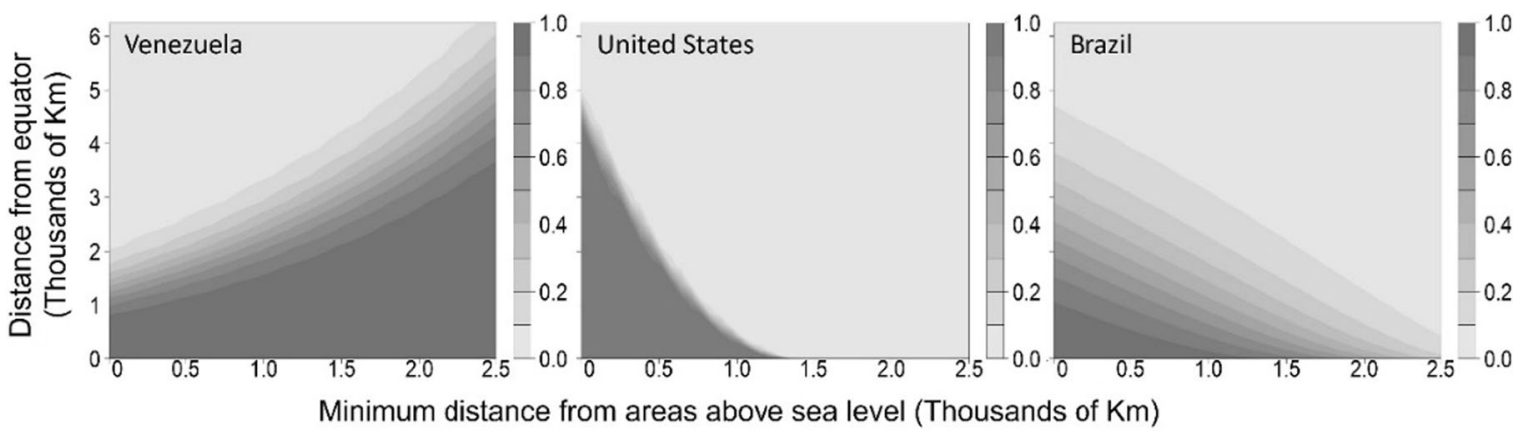

Fig. 5 Effects of the explanatory variables distance from the equator (de) and minimum distance from areas above sea level $\left(d_{(\min )}\right)$ over the proportions sailfish/(sailfish + spearfish) in the fleets of Venezuela, United States and Brazil in the model with year

for almost all fleets. The marginal proportions (mean for the different fleets) predicted based on the estimates of the year factor were always above 0.8, except in 1998 and 2002 (Fig. 4). However, even for these 2 years, in which the estimations of SAI proportions were smaller, the values were above 0.6. Predicted values for the fleets of Venezuela and the United States were above 0.7 in all years, while for Brazil's fleet SAI proportions were lower.

Marginal predictions showed that fleets of Venezuelan and United States tended to capture proportionally much more sailfish than spearfish. The expected proportion of sailfish is also high for Brazil's fleet, but not as much as for the Venezuelan and the United States fleets. The average proportions of sailfish for all fleets were always above 0.9 , being a little higher (above 0.95 ) in the second and fourth quarters. As for quarterly variation differences amongst fleets, an expected value of relatively lower proportion $(\approx 0.7)$ for Brazil's fleet stands out in the third quarter.

To evaluate the effect of the co-variables (distance from the equator and areas above sea level), the predictions of these effects were calculated for each of the fleets in each quarter and, in the case of fleets from Brazil, Venezuela and the United States, the predictions for every year were also estimated. Therefore, for each level of the fleet variable there is a large number of solutions depending on the combination of quarter and year. For example, in the case of Venezuela, whose data are from 1987 to 2008 (21 years), including four quarters, there are $21 \times 4=84$ predictions of the combined effects of the distances from the equator and the areas above the sea level. To illustrate this, the solution to this same fleet calculated for the fourth quarter in 2008 is shown in Fig. 5. This scenario is shown as it is representative of large part (44\%) of the 84 predictions. 
The interpretation of this figure is based on the proportion values attributed to the contours filled in shades of gray. The darker the shade of gray the greater the predicted proportion of sailfish.

Thus, for Venezuela there is a tendency for the sailfish proportion to be greater as it moves away from areas above sea level and as it approaches the equator (Fig. 5-left panel). This pattern was especially evident in the years 1992, 1995 and 1996 for quarters 2 and 3; in the year 2000 for quarters 2, 3 and 4; and in the years 1997 and 2003-2008 for all quarters. In the United States fleet the standard with the highest frequency (41.79\%) indicated that the SAI proportions increase as they approach the equator and areas above sea level (Fig. 5central panel). This characteristic appeared in the years 1992, 1993, 1994 and 2001 in all quarters; in 1995 and 1996 in quarters 2, 3 and 4; in years 1997, 2004 and 2005 in quarters 1 and 4; and in 2003 only in the first quarter. In Brazil the predominant pattern $(35 \%)$ in the different years and quarters was similar to that of the United States, that is, the proportion of sailfish increases as the fishery approaches the equator and areas above sea level (Fig. 5-left panel). This was especially evident in 2005 in the 4th quarter and in 2006-2008 in quarters 1 and 4.

\section{Scenario without year}

To calculate the estimates of sailfish proportions for the fleet factor the same values adopted in the scenario with year were determined for the covariates. Then, sailfish proportions expected for the fleets of Japan, Spain, China Taipei and the United States were higher than for the Brazilian and Venezuelan fleets. The expected marginal proportions of SAI (average for all fleets) were lower in the third quarter. However, it is worth highlighting that there are interactions and differences among the expected values for the combinations of the levels of the factors fleet and quarter. Low expected proportions of sailfish in the third quarter were recorded for Japan and Brazil, but not for the other fleets. Also noteworthy is a reversal of the standard for Venezuela's fleet, for which a higher proportion of sailfish is expected in the third quarter than in the other quarters.

Graphs such as that of Fig. 5 were used in the interpretation of estimates of the expected values of sailfish proportions for the scenario without year, in different combinations of distances from the equator and from areas above sea level. In general, except for estimates calculated for Venezuela, all other fleets indicate an increase in the proportion of sailfish as the fishery gets closer to the equator and areas above sea level. The difference in the calculations for Venezuela is that the proportion of sailfish increases as the fishery approaches the equator but not the areas above the sea level.

\section{Discussion}

According to the estimates the Brazilian fleet tends to present a lower proportion of sailfish and a higher proportion of spearfish in its fisheries, while, in descending order, the fleets of China Taipei, the United States, Spain, and Japan present higher proportions of sailfish. In the case of the US fleet, which has a reduced spatial overlap with the other fleets, the high proportion of sailfish may be related to the specific areas of operation, concentrating fishing efforts in the Gulf of Mexico, North Caribbean and surroundings of Florida (Baum et al. 2003).

The fleets of China Taipei, Spain, and Japan, have some spatial overlap with the Brazilian fleet; however, they act in a more concentrated manner in oceanic areas or areas closer to Africa, while the Brazilian fleet acts mostly in equatorial regions less distant from the South American continent. In addition, the Asian fleets have very different targets from those of the Brazilian fleet. Bigeye (Thunnus obesus) and albacora (Thunnus alalunga) tunas are usually the targets of Asian vessels (Matsumoto and Miyabe 2001; Frédou et al. 2007), while the Brazilian vessels focus on swordfish catches (Xiphias gladius), yellowfin tuna (Thunnus albacares) or even blue shark (Prionace glauca) (Meneses de Lima et al. 2000). These differences in targets and therefore in fishing strategies may be responsible for the difference in the compositions of sailfish and spearfish proportions. The fleet factor covers different nuances; it may reflect differences in targets and strategies as mentioned above, but may also reflect differences in the efficiency of the sampling program, that is, the identification process of sailfish and spearfish. Some fleets may have reported having a higher proportion of sailfish than spearfish, not necessarily because there is a higher catch of the first, but because there may be differences in the accuracy of the identification. A high proportion of sailfish could, for instance, result from 
the inability to recognize and identify spearfish adequately. This may have occurred in the Venezuelan sampling program for a few years (Arocha et al. 2001), but it may also have happened in other countries since spearfish were rarely reported before the year 2000. However, the database we have analyzed was the best scientific information made available by the ICCAT secretariat during the Atlantic sailfish stock assessment meeting held in 2009 (ICCAT 2010). Hence, we assume the database is not strongly biased.

The sailfish proportions are lower in the third quarter (austral winter) for the two scenarios (with and without year) for the Japanese fleet, but especially for the Brazilian fleet. The results calculated for Brazil, which were mainly based on data from the western equatorial region, conflict partially with those of Mourato et al. (2014). These authors classified the area analyzed in this article as a region without spearfish spawning and they found that catch rates of this species were low in this region in the first part of the year, but relatively high in the 3rd and 4th quarters. Perhaps the explanation for the low proportion of sailfish in the third quarter, when catch rates of this species were relatively high in the region (Mourato et al. 2014), is due to an increase in the capture rate of spearfish during this period of the year. This hypothesis must be investigated, but information on SPF until now is even more limited than that for SAI.

The Venezuelan fleet in the third quarter, unlike the Brazilian fleet, had the highest proportions of sailfish in the model adjusted to the data without year. Furthermore, the smaller proportion of SAI for Venezuela was estimated for the first quarter. There is evidence that the spawning of this species in the southwest Caribbean Sea occurs mainly in the middle and at the end of the year, since no mature female was found in the first 2 months of the year (Ariza et al. 2015). Thus, the high proportion of SAI in the Venezuelan catches may be due to greater catchability or density of this species in the southwestern Caribbean waters during the spawning season, which takes place close to summer in the northern hemisphere. In the southern hemisphere Mourato et al. (2014) also reported relatively high catches of sailfish caught with longlines in the southwest Atlantic (South of $20^{\circ} \mathrm{S}$ ), during the spawning season of this species in the austral summer. Therefore, the findings of this and other studies indicate that it is worth investigating the hypothesis that the catchability of sailfish by longline increases in both hemispheres during periods of increased solar radiation, which is closely connected with the reproduction of this species.

There are indeed important changes in the biogeographic patterns of the oceans in both hemispheres in terms of environmental constraints associated with seasonal changes in sunlight, which greatly affect the biology, dynamics and availability of organisms (Longhurst 1998), including vulnerability and nominal catch rates of species of tuna (González-Ania et al. 2001). Temperature is one of the most important physical factors related to equatorial sunshine, affecting feeding, breeding and migratory behavior, as well as body thermoregulation and horizontal and vertical geographical patterns of tuna such as distribution and aggregation of species (Fonteneau 1998). Although the results presented by Mourato et al. (2014) indicated that generic variables such as "area", "month" and "year" had better performance than environmental variables (e.g., sea surface temperature-SST) as explanatory variables in the modeling of sailfish capture rates, the relationship between environmental variables such as SST and the variability in the proportion of SAI (SAI/ $(\mathrm{SAI}+\mathrm{SPF})$ )is worth investigating in order to improve forecasting models for catches of both species.

The density or catchability of Atlantic sailfish compared to spearfish was greater in regions not far from areas above sea level, supporting the literature which states that Atlantic sailfish tend to get close to the coast of the continent, islands and reefs (De Sylva 1974; Nakamura 1985). It is also noteworthy that the proportion of SAI in relation to SPF is relatively higher near the equator. Thus, although there is area overlap and environmental preferences for sailfish and spearfish (Ueyanagi et al. 1970; Nakamura 1985), it is important to highlight that there is some ecological differentiation which implies insignificant changes in the proportion of $\mathrm{SAI}(\mathrm{SAI} /(\mathrm{SAI}+\mathrm{SPF}))$ as a result of the distances from continental and equatorial zones. The relationships between the proportion of sailfish and the distances from the equator and continents are not linear, as indicated by the selection of nonlinear transformations of distances as explanatory variables. The selected transformations indicate that the proportion of sailfish declines rapidly at first with increasing distance, and then to a lesser extent. Thus, despite the fact that the terms used in the GLM are usually linear, it is important to note that in some situations the best performance occurs when the nonlinear terms are included to model the fishery data.

Acknowledgements We would like to thank the Brazilian financing agency CAPES for granting the Master fellowship to Renata Maria Medeiros da Silva. 
Open Access This article is distributed under the terms of the Creative Commons Attribution 4.0 International License (http:// creativecommons.org/licenses/by/4.0/), which permits unrestricted use, distribution, and reproduction in any medium, provided you give appropriate credit to the original author(s) and the source, provide a link to the Creative Commons license, and indicate if changes were made.

\section{References}

Abecassis M, Dewar H, Hawn D, Polovina J (2012) Modeling swordfish daytime vertical habitat in the North Pacific Ocean from pop-up archival tags. Mar Ecol 452:219-236

Akaike H (1974) A new look at the statistical model identification. IEEE Trans Autom Control 19:716-723

Ariza LA, Núñez JG, Narváez M, Medina M, Arocha F (2015) Aspectos reproductivos del pez vela (Istiophorus albicans) en el mar Caribe suroriental y aguas adyacentes del océano Atlántico: un análisis preliminar. Col Vol Sci Pap ICCAT 71(5):2217-2231

Arocha F, Marcano LA, Marcano JS, Gutierrez X, Sayegh J (2001) Captura incidental observada de peces de pico en la pesqueria industrial de palangre Venezolana en el mar Caribe y en el Atlantico centro-occidental: 1991-1999. Col Vol Sci Pap ICCAT 53:131-140

Baum JK, Myers RA, Kehler DG, Worm B, Harley SJ, Doherty PA (2003) Collapse and conservation of shark populations in the Northwest Atlantic. Science 299:389-392

Bellido JM, Santos MB, Pennino MG, Valeiras X, Pierce GJ (2011) Fishery discards and bycatch: solutions for an ecosystem approach to fisheries management? Hydrobiologia 670(1):317-333

Burnham KP, Anderson DR (2002) Model selection and multimodel inference. Springer, New York

Charnes A, Frome EL, Yu PL (1976) The equivalence of generalized least squares and maximum likelihood estimates in the exponential family. J Am Stat Assoc 71:169-171

Cortés E, Arocha F, Beerkircher L, Carvalho F, Domingo A, Heupel M, Holtzhausen H, Santos MN, Ribera M, Simpfendorfer C (2010) Ecological risk assessment of pelagic sharks caught in Atlantic pelagic longline fisheries. Aquat Living Resour 23:25-34

De Sylva DP (1974) A review of the world sport fishery for billfishes (Istiophoridae and Xiphiidae). In: Shomura, RS, Williams F (eds) Proceedings of the international billfish symposium, Kailua-Kona, Hawaii, 9-12 August 1972, Part 2, pp 12-33. Seatle, WA: NOAA Technical Report NMFS SSRF-675

Dobson AJ (2002) An Introduction to generalized linear models. Chapman and Hall, Boca Raton

Fonteneau A (1998) Introduction aux problèmes des relations thons-environnement dans l'Atlantique. Col Vol Sci Pap ICCAT 50(1):275-317

Frédou FL, Frédou T, Travassos P, Lins J, Arfelli C, Andrade HA, Hazin F (2007) Distribution, catch and length composition of the albacore tuna (Thunnus alalunga) caught by the tuna longline fishery in the south Atlantic ocean. Col Vol Sci Pap ICCAT 60(2):518-526

González-Ania LV, Brown CA, Cortés E (2001) Standardized catch rates for yellowfin tuna (Thunnus albacares) in the 1992-1999 Gulf of Mexico longline fishery based upon observer programs from Mexico and the United States. Col Vol Sci Pap ICCAT 53(1):222-237

Goodyear CP (1998) Na analysis of the possible utility of time-area closures to minimize billfish bycatch by U.S. pelagic longlines. Col Vol Sci Pap ICCAT 48(1):263-268

ICCAT (2010) Report of the 2009 sailfish stock assessment. Col Vol Sci Pap ICCAT 65(5):1507-1632

ICCAT (2014) Report of the standing committee on research and statistics (SCRS). ICCAT, Madrid

Longhurst AR (1998) Ecological geography of the sea. Academic Press, California

Matsumoto T, Miyabe N (2001) Report of observer program for Japanese tuna longline fishery in the Atlantic ocean in 2000 (until July). Col Vol Sci Pap ICCAT 52(5):1948-1961

McCullagh P, Nelder JA (1989) Generalized linear models. Chapman and Hall, London-New York

Meneses de Lima JH, Kotas JE, Lin CF (2000) A historical review of the Brazilian long-line fishery and catch of swordfish. Col Vol Sci Pap ICCAT 51(3):1329-1358

Mourato BL, Hazin F, Bigelow K, Musyl M, Carvalho F, Hazin H (2014) Spatio-temporal trends of sailfish, Istiophorus platypterus catch rates in relation to spawning ground and environmental factors in the equatorial and southwestern Atlantic Ocean. Fish Oceanogr 23(1):32-44

Nakamura I (1985) FAO species catalogue. Billfishes of the world: an annotated and illustrated catalogue of marlins, sailfishes, spearfishes and swordfishes known to date, vol 5. FAO, Rome

R Core Team (2015) R: a language and environment for statistical computing. R Foundation for Statistical Computing, Vienna, Austria. http://www.R-project.org/. Accessed 15 Nov 2015

Ueyanagi S, Kikawa S, Uto M, Nishikawa Y (1970) Distribution, spawning, and relative abundance of billfishes in the Atlantic Ocean. Bull Far Seas Fish Res Lab 3:15-45

Veness C (2015) Movable type scripts: calculate distance, bearing and more between latitude/longitude points. World Wide Web publication. http://www.movable-type.co.uk/scripts/latlong.html. Accessed 10 Nov 2015

Watson JW, Kerstetter DW (2006) Pelagic longline fishing gear: a brief history and review of research efforts to improve selectivity. Mar Technol Soc J 40:6-11 